\title{
Patterns and trends of alcohol consumption in rural and urban areas of China: findings from the China Kadoorie Biobank
}

Pek Kei Im ${ }^{1}$, lona Y. Millwood ${ }^{1,2^{*}}$, Yu Guo ${ }^{3}$, Huaidong Du ${ }^{1,2}$, Yiping Chen ${ }^{1,2}$, Zheng Bian ${ }^{3}$, Yunlong $\operatorname{Tan}^{3}$, Zhendong Guo ${ }^{4}$, Shukuan $\mathrm{Wu}^{4}$, Yujie Hua ${ }^{5}$, Liming $\mathrm{Li}^{6}$, Ling Yang ${ }^{1,2+}$, Zhengming Chen ${ }^{1 \dagger}$, on behalf of the China Kadoorie Biobank (CKB) collaborative group

\begin{abstract}
Background: In China, alcohol consumption has increased significantly in recent decades. Little evidence exists, however, about temporal trends in levels and patterns of alcohol consumption and associated factors in adult populations.

Methods: In 2004-08, the China Kadoorie Biobank recruited 512,000 adults (41\% men, mean age 52 years [SD 10.7]) from 10 (5 urban, 5 rural) geographically diverse regions across China, with $\sim 25,000$ randomly selected participants resurveyed in 2013-14. The self-reported prevalence and patterns (e.g., amount, beverage type, heavy drinking episodes) of alcohol drinking at baseline and resurvey were compared and related to socio-demographic, health and other factors.
\end{abstract}

Results: At baseline, 33\% of men drank alcohol at least weekly (i.e., current regular), compared to only $2 \%$ of women. In men, current regular drinking was more common in urban (38\%) than in rural (29\%) areas at baseline. Among men, the proportion of current regular drinkers slightly decreased at resurvey (33\% baseline vs. 29\% resurvey), while the proportion of ex-regular drinkers slightly increased (4\% vs. 6\%), particularly among older men, with more than half of ex-regular drinkers stopping for health reasons. Among current regular drinkers, the proportion engaging in heavy episodic drinking (i.e., > $60 \mathrm{~g} / \mathrm{session}$ ) increased (30\% baseline vs. $35 \%$ resurvey) in both rural (29\% vs. $33 \%$ ) and urban (31\% vs. $36 \%$ ) areas, particularly among younger men born in the 1970 s (41\% vs. $47 \%)$. Alcohol intake involved primarily spirits, at both baseline and resurvey. Those engaging in heavy drinking episodes tended to have multiple other health-related risk factors (e.g., regular smoking, low fruit intake, low physical activity and hypertension).

Conclusions: Among Chinese men, the proportion of drinkers engaging in harmful drinking behaviours increased in the past decade, particularly among younger men. Harmful drinking patterns tended to cluster with other unhealthy lifestyles and health-related risk factors.

Keywords: Alcohol, China, Patterns, Trends

\footnotetext{
*Correspondence: iona.millwood@ndph.ox.ac.uk

Ling Yang and Zhengming Chen are Joint Senior Authors.

${ }^{1}$ Clinical Trial Service Unit and Epidemiological Studies Unit (CTSU), Nuffield

Department of Population Health, University of Oxford, Oxford, UK

${ }^{2}$ Medical Research Council Population Health Research Unit (MRC PHRU),

Nuffield Department of Population Health, University of Oxford, Oxford, UK

Full list of author information is available at the end of the article
}

(c) The Author(s). 2019 Open Access This article is distributed under the terms of the Creative Commons Attribution 4.0 International License (http://creativecommons.org/licenses/by/4.0/), which permits unrestricted use, distribution, and reproduction in any medium, provided you give appropriate credit to the original author(s) and the source, provide a link to the Creative Commons license, and indicate if changes were made. The Creative Commons Public Domain Dedication waiver (http://creativecommons.org/publicdomain/zero/1.0/) applies to the data made available in this article, unless otherwise stated. 


\section{Background}

Globally, alcohol is the seventh leading risk factor for poor health, accounting for $4.2 \%$ of total disability-adjusted life years and $5.2 \%$ of deaths in 2016 [1]. In China, the prevalence of alcohol drinking is lower than in many Western populations, particularly among women [2], which may reflect in part differences in cultural attitudes toward alcohol. While alcohol is traditionally used in festivals and celebration in China, it is also commonly used in the Chinese business world to maintain good relations, particularly by men [3]. Also, social drinking is traditionally widely acceptable among men but not among women in China [3-5]. Moreover, genetic factors may also play a role, as the unpleasant flushing response upon alcohol drinking due to a deficiency in metabolizing alcohol is common in Chinese populations [6]. Despite this, there have been dramatic increases in alcohol availability, production and per capita consumption in China over recent decades due to rapid economic development and urbanisation $[3,7,8]$, which may lead to an increased burden of chronic diseases such as alcohol-related cancers and chronic liver disease, as well as accidents and injuries. Questions remain, however, about changes in patterns of alcohol drinking (e.g., drinking frequency, heavy episodic drinking, beverage types) in adult Chinese populations. Most published studies on alcohol drinking in Chinese populations tended to have small sample sizes, were conducted before 2010, or lacked detailed investigation of drinking patterns [9-17]. Moreover, heterogeneity in the geographical regions covered and definitions used makes it difficult to compare changes in alcohol consumption patterns across previous studies.

While several cross-sectional studies in China reported on drinking patterns during 1994-2007 [9, 12-15], and on drinking prevalence in 2008 and 2011 [10, 16], only one study has attempted to explore the trends of alcohol drinking in general population by using five survey waves from the China Health and Nutrition Survey (CHNS) between 1993 and 2006 [17]. A recently published study explored the increasing trends of alcohol use from 2000 to 2014 using the Chinese Longitudinal Healthy Longevity Survey (CLHLS), but only focused on older adults aged 60 years or above in China [18]. Since 2007 , there have been no reported nationwide studies on drinking patterns and trends in the general population in China. The CHNS study, with around 9000 participants from nine provinces in each wave, showed that levels of alcohol intake and daily drinking in men increased during 1997-2000 but then remained steady until 2006 [17]. Yet, the World Health Organisation (WHO) global status report on alcohol and health, based on recorded alcohol production and trade data, demonstrated a striking increase in per capita alcohol consumption in China between 1978 and 2010 [8, 19]. Large nation-wide epidemiological surveys are needed to provide new evidence on the recent trends of drinking prevalence, and consumption level and drinking patterns among regular drinkers in China.

Longitudinal studies conducted in Western populations have shown that alcohol drinking varies with age throughout the life-course [20-22]. However, to our knowledge, there is no study investigating changes in drinking behaviour at the individual level in China. Furthermore, as stopping drinking can reduce the risk of alcohol-related harm [23], knowledge about the motivations for alcohol cessation could help to inform the development of effective alcohol drinking interventions. However, evidence on the factors and reasons for stopping alcohol drinking in China is limited.

Using data from the China Kadoorie Biobank (CKB) prospective cohort study, we aim to assess: 1) the temporal trends in the prevalence and patterns of alcohol drinking between the baseline survey in 2004-8 and a resurvey in 2013-14, and 2) the socio-demographic, health and other factors associated with changes in drinking prevalence and patterns over this time period.

\section{Methods}

\section{Study design}

The China Kadoorie Biobank (CKB) is a nationwide prospective blood-based cohort study involving 0.5 million participants recruited from 10 geographically defined regions across China, established to investigate genetic and non-genetic causes of many common chronic diseases in the Chinese population. Details of the CKB study design and survey methods have been described previously $[24,25]$. Briefly, the baseline survey was conducted in 2004-8 among 512,891 men and women aged 30-79 years recruited from five rural and five urban regions across China (response rate 30\%), which were selected to cover a wide range of risk factor exposures and disease patterns. The baseline survey involved an interviewer-administered questionnaire, collecting information on demographic and socioeconomic status, lifestyle behaviours (alcohol drinking, smoking, diet, physical activity) and medical history, physical measurements and collection of blood samples. Five-year periodic resurveys of $(\sim 5 \%)$ randomly selected surviving participants were conducted after the baseline survey using similar procedures. For the analyses of temporal trends, we used data from the baseline survey in 2004-8 of 512,891 participants and the resurvey in 2013-14 (mean 8 years [SD 0.8] after baseline) which enrolled 24,996 participants. Among those potentially eligible for the 2013-14 resurvey, the response rate was $\sim 75 \%$ and $0.7 \%$ of participants had died before the time of resurvey. Ethical approval for the study was obtained from 
the ethics committees of the University of Oxford and the Chinese Centre for Disease Control and Prevention. All participants provided written informed consent at baseline and resurveys.

\section{Assessment of alcohol drinking}

Detailed information on questionnaire assessment of alcohol consumption in the CKB study has been described previously [26]. In brief, based on the frequency of alcohol drinking during the past year and prior to the past year, participants were classified into five main drinking categories (see Additional file 1: Table S1 for detailed classifications): abstainers; ex-weekly drinkers; reducedintake drinkers; occasional drinkers; and current weekly drinkers. Current weekly drinkers were asked further questions about their drinking patterns including: (1) drinking frequency; (2) beverage types; (3) amount consumed for each type on a typical drinking day, on special occasions, and the last time they drank; (4) experience of problem drinking indicators; (5) time of drinking in relation to meals; (6) experience of flushing response after drinking; and (7) age of starting drinking weekly. At the resurvey only, ex-weekly and reduced-intake drinkers were asked about their reasons for stopping or reducing drinking.

The amount of pure alcohol consumed in grams per session was calculated according to the beverage type and amount drunk on the last time they drank alcohol (see Additional file 1: Tables S2 and S3 for information on data quality), based on the assumption of the following alcohol content by volume $(v / v)$ typically seen in China [3]: beer $4 \%$, grape wine $12 \%$, rice wine $15 \%$, weak spirits $38 \%$ and strong spirits $53 \%$. Consumption on special occasions was calculated in the same way. Heavy episodic drinking was defined as consuming more than $60 \mathrm{~g}$ of alcohol on one occasion for men, and more than $40 \mathrm{~g}$ for women [27]. The following indicators of problem drinking were reported in the past month: drinking in the morning; unable to work due to drinking; depressed/irritated or loss of control due to drinking; unable to stop drinking; having shakes when stopping drinking.

To describe changes in drinking status at the individual level between baseline and resurvey, six categories were defined: stable non-drinkers; starters; stable drinkers; stoppers; decreased-intake drinkers; and increased-intake drinkers (detailed definition shown in Additional file 1: Table S1).

\section{Assessment of multiple health-related risk factors}

To assess the presence of other health-related risk factors in participants, a risk factor index was derived by summing the individual scores of four major risk factors $(1=$ yes, $0=$ no): regular smoking, lack of daily fresh fruit intake, low physical activity, and hypertension (see Additional file 1: Table S1 for detailed classifications).

\section{Statistical analyses}

As alcohol drinking prevalence and behaviour differed significantly between men and women in CKB, all analyses were conducted separately in men and women. Temporal trends in alcohol drinking were assessed using cross-sectional data from all participants recruited at baseline $(n=512,891)$ and from participants attending the resurvey $(n=24,996)$. The crude prevalence of alcohol drinking and mean consumption were calculated at each survey. Among subgroups defined by socio-demographic factors and the risk factor index, the prevalence of alcohol drinking was directly standardized to the age and region structure of the study population. As drinking patterns were assessed in weekly drinkers, the relevant variables were standardized according to the age and region structure of weekly drinkers. Due to the small number of female weekly drinkers $\left(n_{\text {baseline }}=6248\right.$ and $n_{\text {resurvey }}=292$ ), analyses of drinking patterns by subgroups were conducted in male weekly drinkers only $\left(n_{\text {baseline }}=69,904\right.$ and $\left.n_{\text {resurvey }}=2732\right)$.

Longitudinal analyses of changes in drinking status were conducted among men who attended both surveys $(n=9569)$. A similar standardization approach was applied as above to obtain the prevalence of each status change category standardised to the age and region structure of the longitudinal subset. The statistical association between factors and change in drinking status was tested using logistic regression among baseline non-drinkers and multinomial logistic regression among baseline drinkers. The reasons for stopping weekly drinking were assessed among previous weekly drinkers (i.e. ex-weekly and reduced-intake drinkers) in the resurvey $(n=1166)$. Crude percentages of each of the reasons reported were calculated overall, and by sociodemographics and health factors. Among men who were current weekly drinkers at both baseline and resurvey, a dependent sample t-test was used to test for the statistical significance of change in alcohol consumption at individual level over time. For a quality check of the self-reported alcohol data, associations of blood pressure with alcohol consumption were assessed using linear regression adjusted for age, study region, education, income, smoking category, physical activity and month of recruitment. Data from the CKB Data Release 10 was used in this study. All analyses were performed in SAS version 9.4.

\section{Results}

Of the 512,891 participants recruited at baseline, the mean age was 52 years (SD 10.7), $41 \%$ were men and $56 \%$ were from rural areas. The subset of participants resurveyed $(n=24,996)$ was broadly representative of the 
baseline study population in terms of the distribution of baseline characteristics of sex, birth cohorts, area, education, and health and lifestyle factors (Additional file 1: Table S4). Though the response rates at resurvey were highly consistent across baseline drinking groups, there was slight variation across birth cohorts from $68 \%$ in the oldest and youngest cohorts to $79 \%$ among the middle cohorts (Additional file 1: Table S5). Between baseline and resurvey, there was an increase in household income in the study population (Table 1).

At baseline, 33\% of men but only $2 \%$ of women reported drinking alcohol at least weekly (i.e., current regular drinkers), whereas a third of men and women drank occasionally (Table 2). Among male weekly drinkers, mean alcohol intake was $50 \mathrm{~g} /$ session (based on the last drinking day), with $62 \%$ drinking daily or almost daily (6-7 days/week). The majority of male weekly drinkers engaged in heavy episodic drinking on special occasions $(84 \%)$, with $30 \%$ doing so on the last drinking day, and $24 \%$ reported at least one indicator of problem drinking (e.g., drinking in the morning, unable to work due to drinking etc). Female weekly drinkers had lower mean consumption and were less likely to report heavy episodic drinking or problems related to their drinking. Increased alcohol consumption was associated with higher blood pressure at each survey (Additional file 1: Table S3). In both sexes, strong spirits were the most common beverage type consumed. Most weekly drinkers usually drank with meals $(86 \%$ overall, in men and women), which was broadly consistent across study areas, except for one rural region where $\sim 20 \%$ drank with meals (Additional file 1: Table S6).

Among men, the prevalence of weekly drinking was lower at resurvey than at baseline (33\% baseline vs. $29 \%$ resurvey), as was occasional drinking (38\% vs. $26 \%$ ) (Table 2). Similar differences were also evident in women for occasional drinking (34\% vs. 15\%). Among male weekly drinkers, however, there were increases in mean consumption on the last drinking day $(50 \mathrm{~g} / \mathrm{session}$ vs. $56 \mathrm{~g} / \mathrm{ses}$ sion), and in the prevalence of heavy episodic drinking ( $30 \%$ vs. $35 \%)$ and daily drinking (62\% vs. $71 \%)$ during the same period. Further analyses among men who drank weekly at both baseline and resurvey showed that mean consumption increased by $3.7 \mathrm{~g} /$ session $(p=0.004)$ (Additional file 1: Table S7). While the most common beverage type was strong spirits only (consumed by $42 \%$ of male weekly drinkers at both surveys), there was an increase in the proportion of drinkers consuming multiple beverage types ( $8 \%$ vs. $16 \%$ ), who tended to have a higher intake per session than those drinking a single beverage type (Additional file 1: Table S8). Similar drinking patterns and temporal trends were observed in the subset of participants who were involved in both the baseline survey and resurvey (Additional file 1: Table S9).
Among men, the patterns and trends of alcohol drinking differed by birth cohort (Fig. 1a-1d). At baseline, weekly drinking prevalence was highest in men born in the 1950s-60s (36\%) (Fig. 1a). Over the study period, the prevalence of weekly drinking decreased in most birth cohorts, except for the youngest cohort born in the 1970s who had a slightly higher prevalence of weekly drinking at resurvey (27\% vs. $32 \%)$, which may be due to the effects of age (Additional file 1: Figure S1). Among male weekly drinkers in both surveys, drinking frequency was higher among older birth cohorts (Fig. 1b), but mean consumption per session and the prevalence of heavy episodic drinking were higher among younger birth cohorts and increased over time in these groups ( $58 \mathrm{~g} /$ session vs. $77 \mathrm{~g} /$ session and $41 \%$ vs. $47 \%$ respectively in men born in the 1970s) (Fig. 1c, d).

Drinking patterns also differed by study area and socio-economic status in men at both surveys. The prevalence of weekly drinking was higher in urban areas, while the proportion of daily drinkers and men reporting problem drinking indicators among those who drank at least weekly was higher in rural areas and lower socio-economic groups (Additional file 1: Tables S10 and S11). Over time, a more marked increase in mean alcohol consumption was observed among urban drinkers. The prevalence of men who reported at least one problem drinking indicator increased in urban areas and particularly in younger urban drinkers, but generally declined in rural areas (Additional file 1: Table S12). Furthermore, younger generations also had a higher tendency to drink beer or multiple beverage types, with a notable rise in the proportion of mixed-beverage drinkers between baseline and resurvey (10\% vs. $25 \%$ in those born in the 1970s) (Additional file 1: Figure S2).

Having multiple health-related risk factors (i.e. regular smoking, low physical activity, low fresh fruit intake, hypertension) was correlated with alcohol drinking, with weekly drinking prevalence, drinking frequency, mean consumption and heavy episodic drinking prevalence all increasing with the number of risk factors in men at both surveys (Fig. 2a-d). When hypertension was removed from the risk factor index, the correlation persisted between unhealthy lifestyles and alcohol drinking (Additional file 1: Figure S3).

Among 9569 men who attended both surveys, during $2004-8$ and $2013-14,40 \%$ of them continually drank and $18 \%$ did not drank alcohol on both occasions, 23\% stopped drinking and $4 \%$ started drinking since baseline (Table 3). Men who were older, living in rural areas or with poor self-reported health status at resurvey were more likely to remain non-drinking as well as to have stopped drinking. The results were consistent though less apparent 
Table 1 Cross-sectional characteristics of participants at baseline (2004-8) and resurvey (2013-14)

\begin{tabular}{|c|c|c|c|c|}
\hline \multirow[t]{2}{*}{ Characteristics $^{*}$} & \multicolumn{2}{|l|}{ Men } & \multicolumn{2}{|l|}{ Women } \\
\hline & Baseline $(N=210,259)$ & Resurvey $(N=9569)$ & Baseline $(N=302,632)$ & Resurvey $(N=15,427)$ \\
\hline \multicolumn{5}{|l|}{ Socio-demographic characteristics } \\
\hline Mean age, years & 52.4 & 59.7 & 51.0 & 58.5 \\
\hline \multicolumn{5}{|l|}{ Birth cohorts, \% } \\
\hline$<1940$ & 13.8 & 11.6 & 10.3 & 8.6 \\
\hline 1940-1949 & 22.4 & 24.2 & 20.6 & 22.2 \\
\hline 1950-1959 & 30.9 & 32.9 & 32.2 & 34.4 \\
\hline 1960-1969 & 27.9 & 27.5 & 31.3 & 30.5 \\
\hline$\geq 1970$ & 4.9 & 3.9 & 5.7 & 4.3 \\
\hline \multicolumn{5}{|l|}{ Area, \% } \\
\hline Rural & 56.6 & 56.8 & 55.4 & 57.1 \\
\hline \multicolumn{5}{|l|}{ Highest education, \% } \\
\hline No formal education & 8.9 & 9.2 & 25.3 & 27.1 \\
\hline Primary school & 33.4 & 33.4 & 31.4 & 31.4 \\
\hline Middle or high school & 49.9 & 49.2 & 38.8 & 37.4 \\
\hline Technical school/college or above & 7.9 & 8.2 & 4.5 & 4.2 \\
\hline \multicolumn{5}{|l|}{ Household income (yuan/year), \% } \\
\hline$<10,000$ & 26.0 & 8.2 & 29.8 & 9.0 \\
\hline $10,000-19,999$ & 28.3 & 11.2 & 29.6 & 13.0 \\
\hline $20,000-34,999$ & 25.4 & 17.9 & 24.2 & 20.2 \\
\hline $35,000+$ & 20.2 & 62.7 & 16.5 & 57.8 \\
\hline \multicolumn{5}{|l|}{ Health and lifestyle factors } \\
\hline Regular smoking, \% & 61.1 & 51.0 & 2.4 & 1.6 \\
\hline Daily fruit intake, $\%$ & 23.0 & 39.0 & 31.8 & 48.8 \\
\hline Physical activity, mean MET hours/day & 22.0 & 21.1 & 20.4 & 18.4 \\
\hline Self-reported good healtha, \% & 49.2 & 47.0 & 43.3 & 41.8 \\
\hline Prior disease ${ }^{b}, \%$ & 22.6 & 31.7 & 22.1 & 33.9 \\
\hline Satisfied with life ${ }^{c}, \%$ & 69.7 & 82.4 & 67.7 & 80.5 \\
\hline \multicolumn{5}{|l|}{ Physical measurements } \\
\hline Mean SBP, mmHg & 132.8 & 136.9 & 129.9 & 136.3 \\
\hline Mean DBP, mmHg & 79.2 & 79.6 & 76.8 & 77.5 \\
\hline Mean heart rate, beats/minute & 77.7 & 76.6 & 79.7 & 78.2 \\
\hline Mean $\mathrm{BMl}, \mathrm{kg} / \mathrm{m}^{2}$ & 23.4 & 24.0 & 23.8 & 24.3 \\
\hline Mean WHR & 0.9 & 0.9 & 0.9 & 0.9 \\
\hline Mean standing height, $\mathrm{cm}$ & 165.2 & 164.7 & 154.1 & 153.5 \\
\hline
\end{tabular}

$B M I$ body mass index, S/DBP systolic/diastolic blood pressure, MET metabolic equivalent task, WHR waist-hip ratio

${ }^{*}$ Characteristics were based on the characteristics of the participants collected at each of the baseline and the resurvey

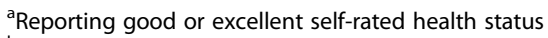

${ }^{b}$ Diagnosed with one or more of: coronary heart disease, stroke, transient ischaemic attack, diabetes, cancer, tuberculosis, chronic hepatitis/cirrhosis, rheumatoid arthritis, peptic ulcer, chronic respiratory disease, gallstone/gallbladder disease, kidney disease

${ }^{\mathrm{c}}$ Reporting being satisfied or very satisfied with life

when analyses used baseline rather than resurvey characteristics (Additional file 1: Table S13), suggesting that changes in health status and ageing over the study period was correlated with stopping drinking. Similarly, among the 1166 ex-weekly or reduced-intake drinkers in the resurvey, over half of them reported existing physical illness as their main reason for stopping weekly drinking, particularly in those who were older or had prior diseases (Table 4). Other reported reasons for stopping drinking were money (24\%), future health concerns (6\%), and other reasons not related to financial or health concerns (19\%). 
Table 2 Prevalence and patterns of alcohol consumption at baseline (2004-2008) and resurvey (2013-2014), by sex

\begin{tabular}{|c|c|c|c|c|}
\hline & \multicolumn{2}{|l|}{ Men } & \multicolumn{2}{|l|}{ Women } \\
\hline & Baseline & Resurvey & Baseline & Resurvey \\
\hline \multicolumn{5}{|l|}{ Overall } \\
\hline Number of participants & 210,259 & 9569 & 302,632 & 15,427 \\
\hline \multicolumn{5}{|l|}{ Drinking categories, \% } \\
\hline Abstainer & 20.4 & 34.9 & 63.6 & 82.0 \\
\hline Ex-weekly & 3.8 & 6.3 & 0.4 & 0.7 \\
\hline Reduced-intake & 4.9 & 3.8 & 0.4 & 0.5 \\
\hline Occasional & 37.7 & 26.4 & 33.5 & 14.9 \\
\hline Current weekly & 33.2 & 28.6 & 2.1 & 1.9 \\
\hline \multicolumn{5}{|l|}{ Among current weekly drinkers } \\
\hline Number of participants & 69,904 & 2732 & 6248 & 292 \\
\hline \multicolumn{5}{|l|}{ Types consumed^, \% } \\
\hline Strong spirit ( $\geq 40 \%$ alcohol) only & 41.5 & 41.8 & 47.6 & 39.4 \\
\hline Weak spirit (<40\% alcohol) only & 19.8 & 16.0 & 11.4 & 12.0 \\
\hline Beer only & 20.1 & 13.5 & 22.6 & 12.3 \\
\hline Rice wine or grape wine only & 11.0 & 12.3 & 15.7 & 27.1 \\
\hline Mixed & 7.7 & 16.3 & 2.7 & 9.2 \\
\hline Mean consumption, g/session^ & 49.9 & 55.6 & 22.7 & 24.1 \\
\hline \multicolumn{5}{|l|}{ Number of drinking days per week, $\%$} \\
\hline $1-2$ & 19.9 & 14.9 & 33.1 & 21.9 \\
\hline $3-5$ & 18.0 & 14.0 & 21.6 & 15.4 \\
\hline $6-7$ & 62.1 & 71.1 & 45.2 & 62.7 \\
\hline \multicolumn{5}{|l|}{ Types consumed on special occasions, \% } \\
\hline Strong spirit ( $\geq 40 \%$ alcohol) only & 35.7 & 35.8 & 41.4 & 33.9 \\
\hline Weak spirit ( $<40 \%$ alcohol) only & 16.3 & 14.7 & 9.9 & 10.6 \\
\hline Beer only & 10.9 & 8.4 & 16.7 & 11.0 \\
\hline Rice wine or grape wine only & 6.6 & 9.3 & 12.3 & 25.7 \\
\hline Mixed & 30.5 & 31.8 & 19.6 & 18.8 \\
\hline Mean consumption on special occasions, g/occasion & 147.4 & 116.3 & 55.1 & 41.3 \\
\hline \multicolumn{5}{|l|}{ Drinking patterns, $\%$} \\
\hline Drinking outside meal. & 14.1 & 17.6 & 13.8 & 20.9 \\
\hline Heavy episodic drinking ${ }^{\wedge a}$ & 29.8 & 34.7 & 18.2 & 17.8 \\
\hline Heavy episodic drinking on special occasions ${ }^{a}$ & 83.6 & 72.9 & 57.1 & 43.8 \\
\hline Problem drinking indicator $(s)^{b}$ & 23.9 & 23.8 & 9.8 & 9.2 \\
\hline Flushing response after drinking & 17.9 & 15.5 & 23.6 & 13.7 \\
\hline Mean age started weekly drinking & 28.7 & 29.3 & 37.7 & 40.4 \\
\hline
\end{tabular}

${ }^{\mathrm{a}}$ Heavy drinking episode is defined as drinking $>60 \mathrm{~g}$ of pure alcohol in one session for men and $>40 \mathrm{~g}$ for women

${ }^{\mathrm{b}}$ Reporting one or more in the past month of: drinking in the morning; unable to work or do anything due to drinking; depressed, irritated or lost control due to drinking; couldn't stop drinking; had shakes when stopped drinking

${ }^{\wedge}$ Based on alcohol intake data reported on the last time the participants drank

\section{Discussion}

This large study examines recent patterns and trends of alcohol drinking and factors associated with stopping drinking in urban and rural areas of China. Overall, there was a modest decline in weekly drinking prevalence between 2004 and 2013 as the study population became older, but a modest increase in mean consumption, drinking frequency and heavy episodic drinking prevalence among men who drank alcohol weekly. Younger age and having multiple health-related risk factors were important correlates of heavy drinking patterns. Older and less healthy men were more likely to 


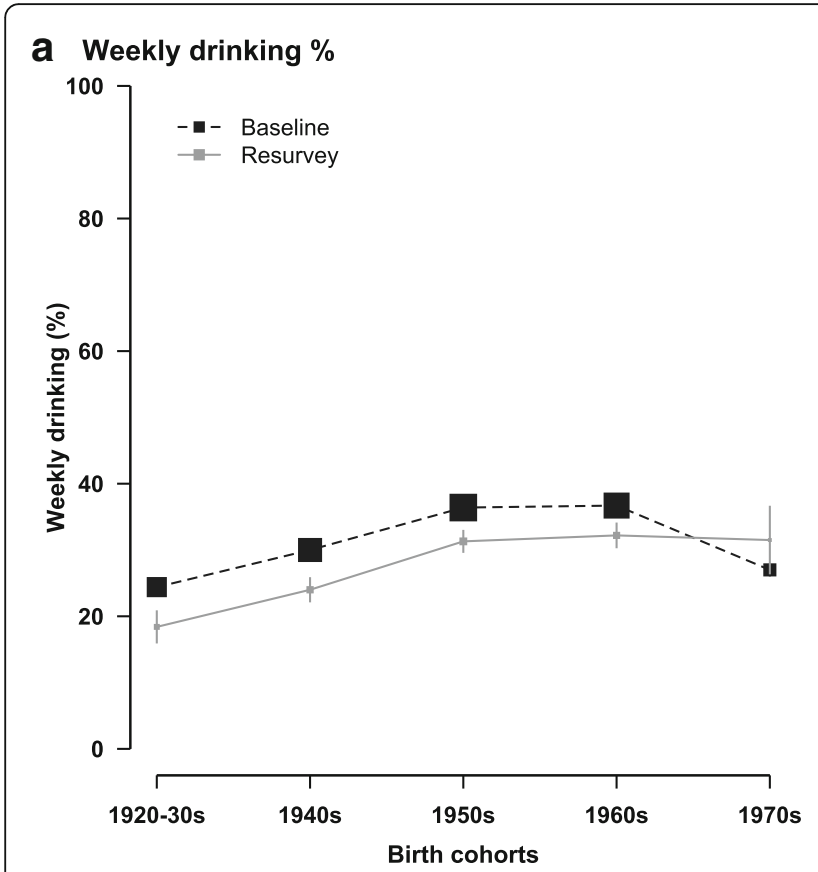

\section{b Drinking frequency}

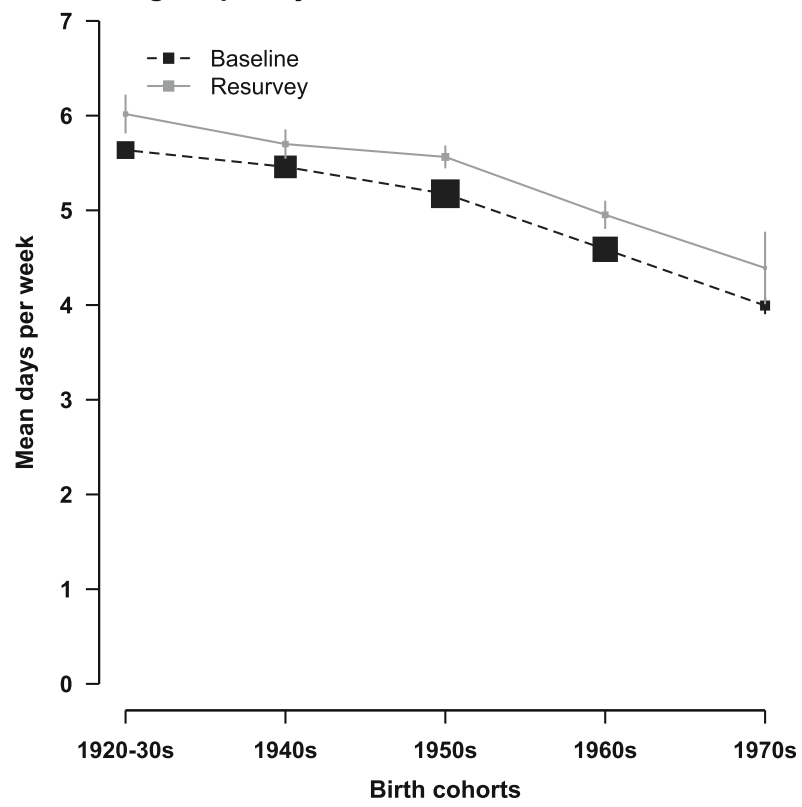

C Mean consumption per session

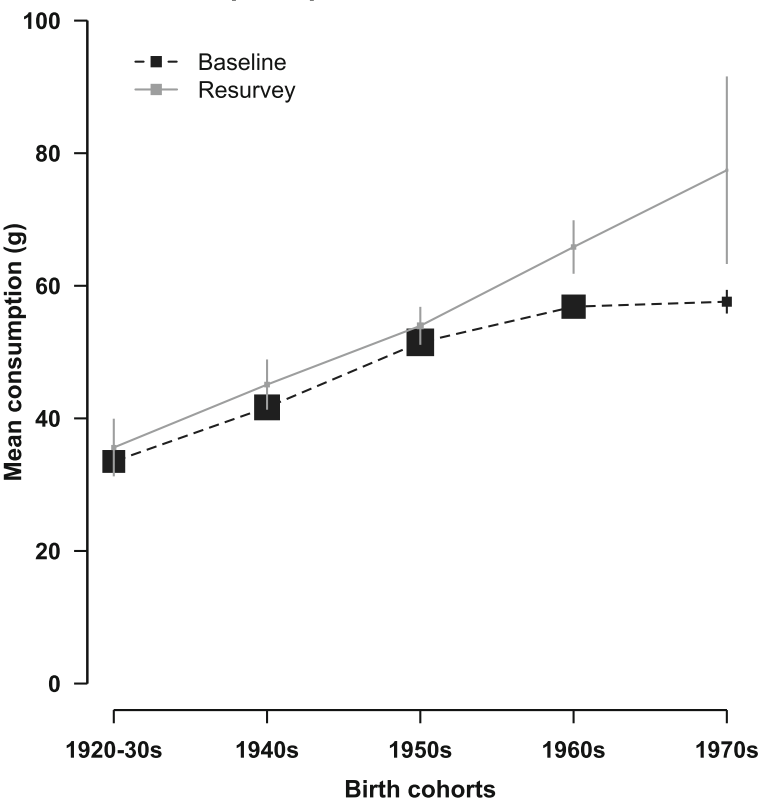

d Heavy episodic drinking \%

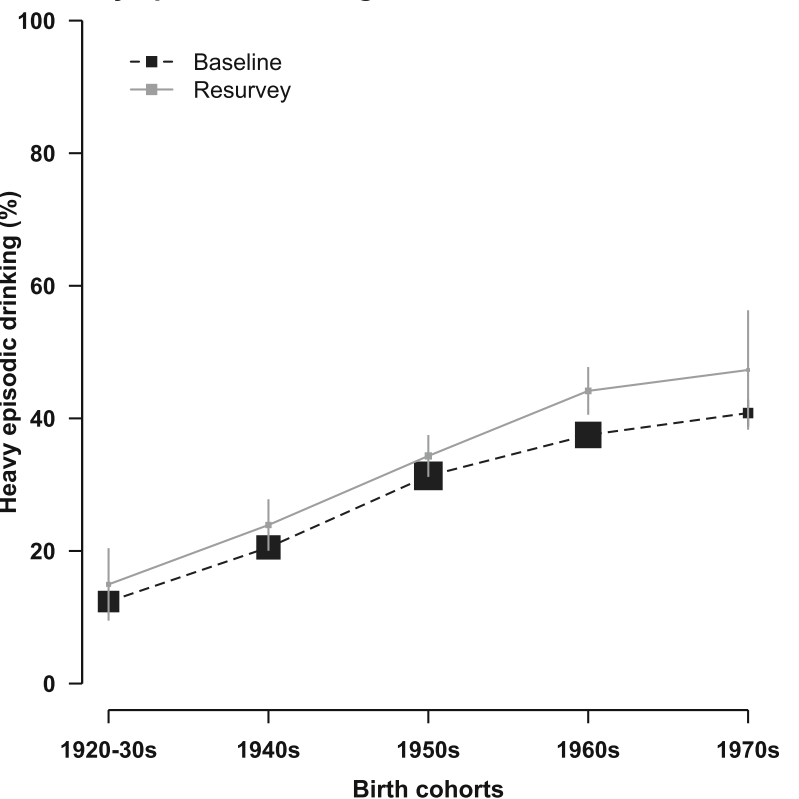

Fig. 1 Alcohol drinking characteristics in male weekly drinkers in 2004-8 and 2013-4, by birth cohort. Prevalence and mean were adjusted for regions. Size of boxes is proportional to the sample size of the respective birth cohort. Error bars are $95 \%$ confidence intervals. Mean consumption per session ( $\mathrm{g} / \mathrm{session}$ ) and heavy episodic drinking was based on alcohol intake data reported on the last time the participants drank. Heavy episodic drinking is defined as drinking $>60 \mathrm{~g}$ of pure alcohol in one session for men. All men at baseline $(n=210,259)$ and resurvey $(n=9569)$ were included in (a). All male weekly drinkers at baseline $(n=69,904)$ and resurvey $(n=2732)$ were included in $(\mathbf{b}-\mathbf{d})$

stop drinking, suggesting that existing illness was a major reason for stopping drinking in this Chinese population.

The findings on drinking prevalence in our study are broadly consistent with previous nationwide cross-sectional surveys at particular time point in China during 2002-2011 $[10,12,13]$. A study involving 160,000 participants aged 15 + years from the China National Nutrition and Health Survey (CNNHS) found a similar weekly drinking prevalence of $39.6 \%$ in men and $4.5 \%$ in women in 2002 [13]. The 

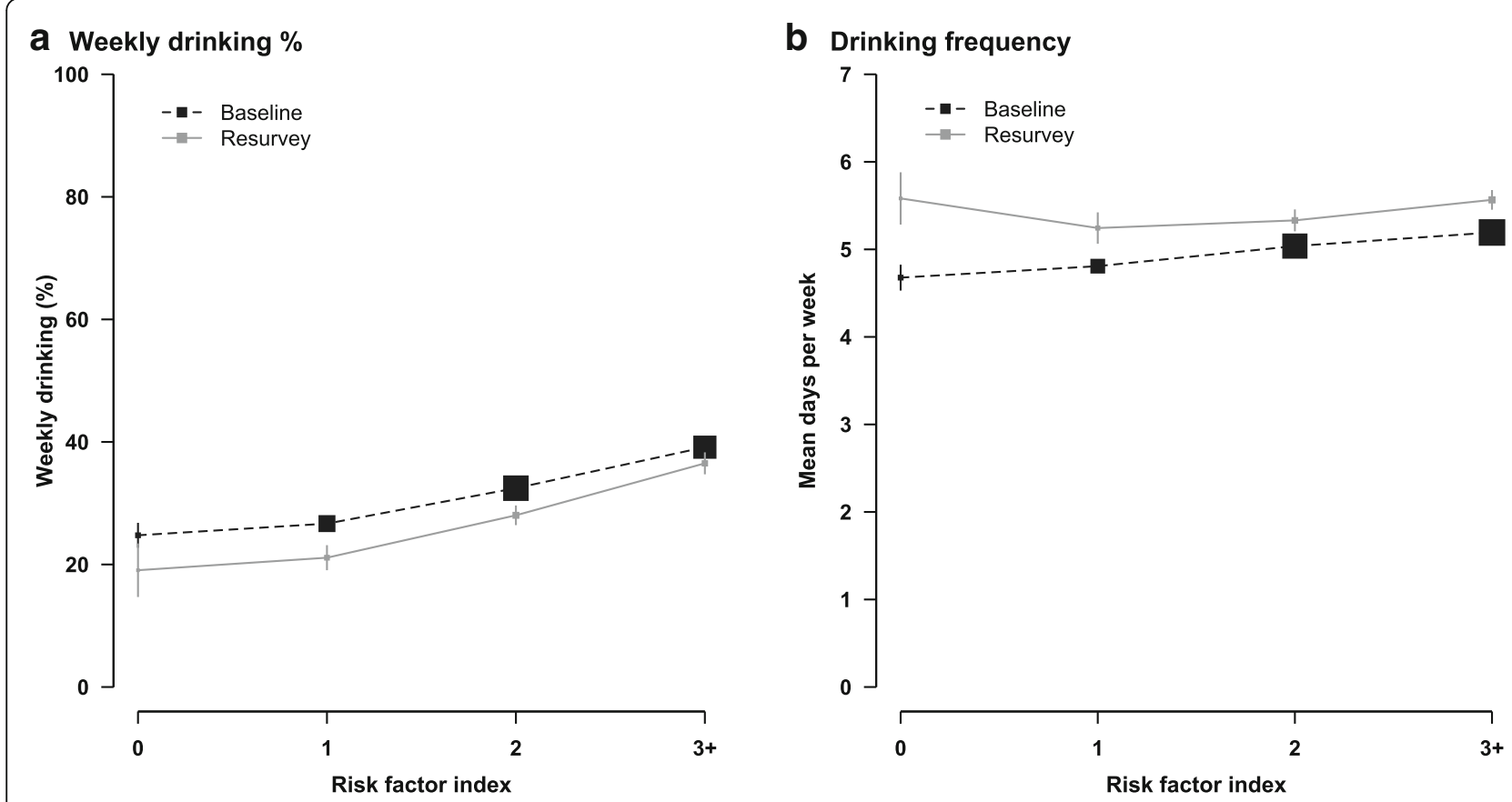

C Mean consumption per session

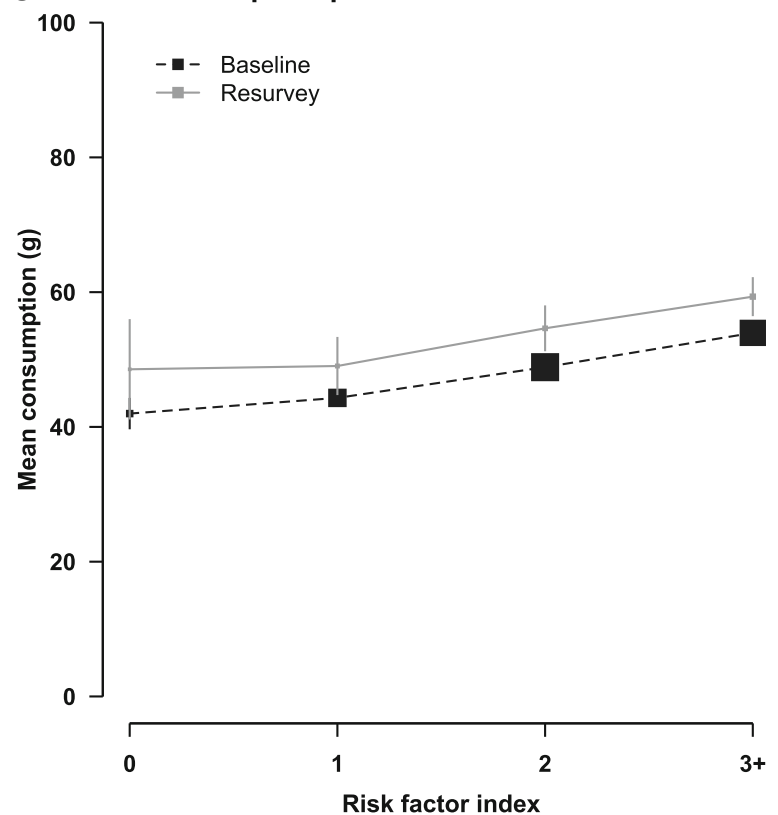

d Heavy episodic drinking \%

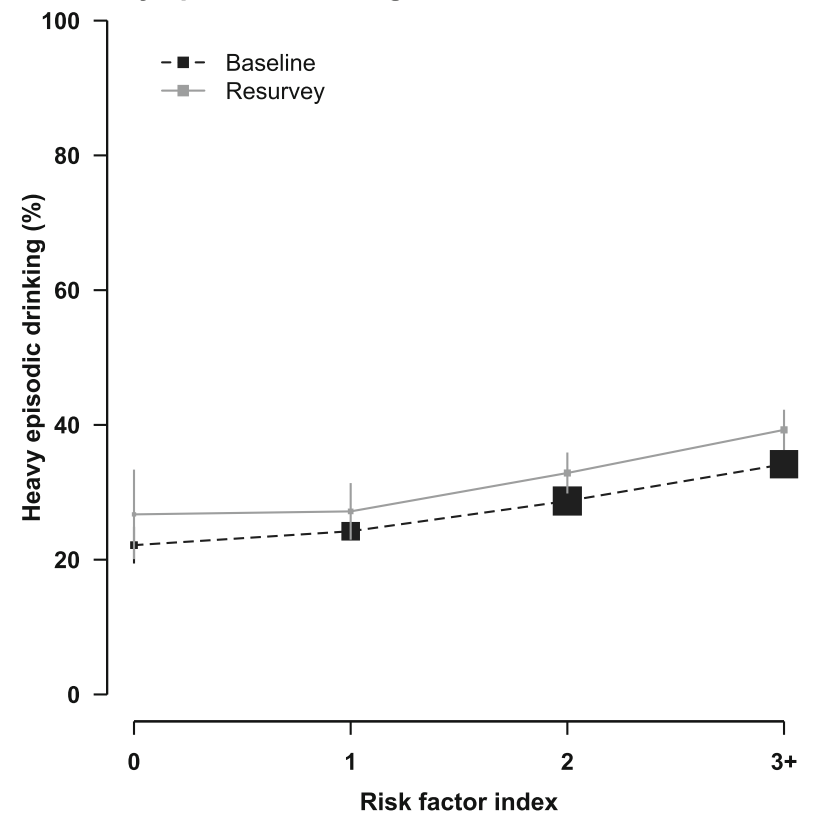

Fig. 2 Alcohol drinking characteristics in male weekly drinkers in 2004-8 and 2013-4, by health-related risk factor index. Prevalence and mean were adjusted for age and regions. Size of boxes is proportional to the sample size of the respective risk factor index group. Error bars are $95 \%$ confidence intervals. Mean consumption per session (g/session) and heavy episodic drinking was based on alcohol intake data reported on the last time the participants drank. Heavy episodic drinking is defined as drinking $>60 \mathrm{~g}$ of pure alcohol in one session for men. Risk factor index was derived by summing the individual scores of each of the four risk factors ( 0 if no, 1 if yes): regular smoking, lack of daily fruit intake, hypertension, low physical activity. All men at baseline $(n=210,259)$ and resurvey $(n=9569)$ were included in $(\mathbf{a})$. All male weekly drinkers at baseline $(n=69,904)$ and resurvey $(n=2732)$ were included in $(\mathbf{b}-\mathbf{d})$ 
Table 3 Changes in drinking status by socio-demographic characteristics and health factors among men from baseline to resurvey

\begin{tabular}{|c|c|c|c|c|c|c|c|}
\hline \multirow[t]{2}{*}{ Characteristics* } & \multirow[t]{2}{*}{$\mathrm{N}$} & \multicolumn{2}{|c|}{$\begin{array}{l}\text { Non-drinkers (abstainers, ex- } \\
\text { weekly drinkers) at baseline }\end{array}$} & \multicolumn{4}{|c|}{ Drinkers (reduced-intake, occasional and weekly drinkers) at baseline ${ }^{\#}$} \\
\hline & & Stable non-drinker \% & Starter \% & Stable drinker \% & Stopper \% & Decreased-intake drinker \% & Increased-intake drinker \% \\
\hline All men & 9569 & 18.3 & 4.2 & 40.0 & 22.9 & 8.2 & 6.3 \\
\hline \multicolumn{8}{|c|}{ Socio-demographic characteristics } \\
\hline \multicolumn{8}{|l|}{ Birth cohorts } \\
\hline$<1940$ & 1106 & 33.0 & 4.3 & 24.0 & 30.6 & 3.9 & 4.3 \\
\hline 1940-1949 & 2311 & 23.1 & 4.3 & 32.4 & 28.3 & 6.9 & 5.2 \\
\hline 1950-1959 & 3149 & 16.3 & 3.8 & 43.7 & 22.1 & 8.2 & 6.0 \\
\hline 1960-1969 & 2632 & 11.3 & 4.6 & 47.3 & 18.1 & 10.7 & 8.0 \\
\hline$\geq 1970$ & 371 & 8.3 & 3.7 & 50.3 & 16.0 & 11.7 & 10.0 \\
\hline \multicolumn{8}{|l|}{ Area } \\
\hline Rural & 5433 & 21.9 & 4.3 & 36.3 & 24.5 & 6.9 & 6.1 \\
\hline Urban & 4136 & 13.6 & 4.1 & 44.8 & 20.9 & 10.0 & 6.6 \\
\hline \multicolumn{8}{|l|}{ Highest education } \\
\hline Primary or below & 4076 & 20.1 & 4.2 & 36.9 & 24.1 & 8.6 & 6.1 \\
\hline Middle or above & 5493 & 16.7 & 3.9 & 42.1 & 22.5 & 8.4 & 6.4 \\
\hline \multicolumn{8}{|c|}{ Household income (yuan/year) } \\
\hline$<35,000$ & 3573 & 21.5 & 3.9 & 37.0 & 23.9 & 6.8 & 7.0 \\
\hline $35,000+$ & 5996 & 16.8 & 4.4 & 40.8 & 22.9 & 8.9 & 6.2 \\
\hline \multicolumn{8}{|l|}{ Health factors } \\
\hline \multicolumn{8}{|c|}{ Self-reported health status ${ }^{\mathrm{a}}$} \\
\hline Good & 4498 & 16.7 & 4.4 & 43.2 & 20.0 & 8.4 & 7.3 \\
\hline Poor & 5071 & 19.9 & 4.0 & 37.0 & 25.6 & 8.1 & 5.4 \\
\hline \multicolumn{8}{|l|}{ Prior disease ${ }^{b}$} \\
\hline No & 6533 & 17.0 & 3.9 & 42.6 & 21.3 & 8.5 & 6.7 \\
\hline Yes & 3036 & 21.4 & 5.1 & 34.3 & 26.4 & 7.6 & 5.1 \\
\hline \multicolumn{8}{|c|}{ Risk factor index score ${ }^{c}$} \\
\hline 0 & 469 & 18.1 & 5.4 & 36.7 & 25.5 & 7.9 & 6.3 \\
\hline 1 & 1962 & 18.3 & 4.6 & 36.8 & 24.9 & 9.6 & 5.8 \\
\hline 2 & 3559 & 18.4 & 4.7 & 40.1 & 23.0 & 7.4 & 6.4 \\
\hline $3+$ & 3579 & 17.4 & 3.5 & 43.1 & 21.1 & 8.2 & 6.7 \\
\hline
\end{tabular}

Prevalence at subgroup levels is adjusted for age and regions as appropriate

*Except for age and regions, characteristics were based on the characteristics of the participants collected at the resurvey

Among baseline non-drinkers, associations between change in drinking status and factors were tested by logistic regression adjusting for age and region: $p<0.001$ for trend across birth cohorts and $p<0.02$ for heterogeneity across regions, income and self-reported health

\#Among baseline drinkers, associations between change in drinking status and factors were tested by multinomial logistic regression adjusting for age and region: $p<0.02$ across all variables except education

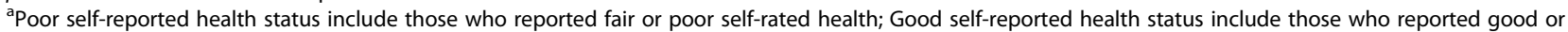
excellent self-rated health

${ }^{b}$ Diagnosed with one or more of: coronary heart disease, stroke, transient ischaemic attack, diabetes, cancer, tuberculosis, chronic hepatitis/cirrhosis, rheumatoid arthritis, peptic ulcer, chronic respiratory disease, gallstone/gallbladder disease, kidney disease

'Derived by summing the individual scores of each of the four risk factors ( 0 if no, 1 if yes): regular smoking, lack of daily fruit intake, hypertension, low physical activity

latest wave of the CHNS in $2011(n=12,658)$ showed a prevalence of past-year ever drinking of $59 \%$ in men, which is comparable to that in our resurvey, but did not report on drinking frequency or other drinking patterns [10]. With detailed information on drinking patterns at two surveys approximately 8 years apart, our study showed a modest decrease in weekly drinking prevalence over time since
2004, similar to findings observed in a previous study of US men and women aged 45-64 years, sampled 6 years apart [20]. This may be due to ageing in the study population and the "sick-quitter" effect [28], as suggested by the associations of older age and poor health with stopping drinking in our study. Interestingly, despite the decreased drinking prevalence, we observed modest increases in mean alcohol 
Table 4 Reasons for stopping drinking by socio-demographic characteristics and health factors among previous weekly drinkers at resurvey (2013-2014)

\begin{tabular}{|c|c|c|c|c|c|}
\hline \multirow[t]{2}{*}{ Characteristics $^{*}$} & \multirow[t]{2}{*}{$\mathrm{N}$} & \multicolumn{4}{|l|}{ Reasons } \\
\hline & & Existing illness (\%) & Money (\%) & Future health^ $(\%)$ & Other" ${ }^{\#}(\%)$ \\
\hline Overall & 1166 & 51.9 & 23.6 & 5.8 & 18.7 \\
\hline \multicolumn{6}{|c|}{ Socio-demographic characteristics } \\
\hline \multicolumn{6}{|l|}{ Gender } \\
\hline Men & 970 & 53.1 & 24.3 & 6.3 & 16.3 \\
\hline Women & 196 & 45.9 & 19.9 & 3.6 & 30.6 \\
\hline \multicolumn{6}{|l|}{ Birth cohorts } \\
\hline$<1940$ & 174 & 56.9 & 17.8 & 5.7 & 19.5 \\
\hline 1940-1949 & 408 & 57.4 & 21.1 & 5.4 & 16.2 \\
\hline 1950-1959 & 381 & 47.2 & 27.3 & 7.1 & 18.4 \\
\hline$\geq 1960$ & 203 & 45.3 & 26.6 & 4.4 & 23.6 \\
\hline \multicolumn{6}{|l|}{ Area } \\
\hline Rural & 687 & 60.3 & 21.5 & 6.3 & 11.9 \\
\hline Urban & 479 & 39.9 & 26.5 & 5.2 & 28.4 \\
\hline \multicolumn{6}{|l|}{ Highest education } \\
\hline Primary or below & 589 & 60.1 & 20.4 & 7.0 & 12.6 \\
\hline Middle or above & 577 & 43.5 & 26.9 & 4.7 & 25.0 \\
\hline \multicolumn{6}{|c|}{ Household income (yuan/year) } \\
\hline$<35,000$ & 487 & 58.5 & 23.2 & 5.3 & 12.9 \\
\hline $35,000+$ & 679 & 47.1 & 23.9 & 6.2 & 22.8 \\
\hline \multicolumn{6}{|l|}{ Health factors } \\
\hline \multicolumn{6}{|c|}{ Self-reported health status ${ }^{a}$} \\
\hline Good & 408 & 42.9 & 26.0 & 7.1 & 24.0 \\
\hline Poor & 758 & 56.7 & 22.3 & 5.1 & 15.8 \\
\hline \multicolumn{6}{|l|}{ Prior disease ${ }^{b}$} \\
\hline No & 618 & 44.8 & 27.0 & 6.5 & 21.7 \\
\hline Yes & 548 & 59.9 & 19.7 & 5.1 & 15.3 \\
\hline
\end{tabular}

*Except for age and regions, characteristics were based on the characteristics of the participants collected at the resurvey

^Included health concerns about future illness and doctor's advice

"Included family disapproval and other reasons apart from health and financial concern

${ }^{a}$ Poor self-reported health status include those who reported fair or poor self-rated health; Good self-reported health status include those who reported good or excellent self-rated health

${ }^{b}$ Diagnosed with one or more of: coronary heart disease, stroke, transient ischaemic attack, diabetes, cancer, tuberculosis, chronic hepatitis/cirrhosis, rheumatoid arthritis, peptic ulcer, chronic respiratory disease, gallstone/gallbladder disease, kidney disease

consumption per drinking session and in the prevalence of daily drinking and heavy episodic drinking, among male weekly drinkers, which is consistent with the increasing per capita alcohol consumption in China shown in the WHO report $[8,19]$. This is in contrast to patterns observed in many Western populations, for example, a decreasing trend in alcohol consumption levels during 1990s-2010s among adults aged 18-85 years in Switzerland [29] and in other southern, central-western and western European countries [30], and a reduction in frequent drinking $(5+$ days in the previous week) among adults aged over 16 years during 2005-2017 in the United Kingdom [31].
Previous studies in China conducted in the 2000s reported that harmful drinking patterns peaked between the ages of $30-60$ years in men $[12,15]$. These studies, however, used rather low thresholds to define harmful drinking (e.g., $>25 \mathrm{~g}$ or $>50 \mathrm{~g} /$ day for excessive or binge drinking in men). In our study, using the WHO recommended threshold for high-risk drinking episodes $(>60$ $\mathrm{g} / \mathrm{session}$ in men) [27], we showed that younger men were more likely to report heavy drinking episodes, and further showed an increase in prevalence of heavy episodic drinking during the study period. While the Chinese custom of spirit drinking [12, 13, 32] and drinking with meals remained steady throughout our study 
period, our findings revealed a rise in drinking mixed beverage types, particularly in younger men. This shift is likely the result of exposure to a wider availability of alcoholic beverages brought by the rapid economic development and westernisation in modern China. Importantly, a rise in drinking multiple beverage types among young Chinese men is of public health concern, since drinkers seemed to drink more in each session when they consumed multiple beverage types.

As in the present study, previous studies in England and Hong Kong also reported the clustering of heavy drinking with smoking, low fruit and vegetables intake and low exercise [33,34], in settings where the lifestyle behavioural patterns differed from those in mainland of China. Previous studies have shown that people with multiple risk factors, combined with heavy drinking, had higher risks for adverse health outcomes [35-37]. Though the prevalence of smoking may have slightly decreased in China in the last decade, overall cigarette consumption has increased over time [38, 39], as has tobacco-attributed mortality [40]. Given the consistently growing tobacco-attributed burden and alcohol epidemic, particularly among men, and the shift to sedentary lifestyles in China which is accelerated by urbanisation, the consequences of these rapid lifestyle transitions may emerge in an increased chronic disease burden [41].

One important step in alcohol policy development is to understand the triggers for drinking cessation in Chinese populations. Our findings that existing illness was the most reported reason for stopping weekly drinking are generally consistent with a study of 14,000 participants in China in the 1990s [11]. However, concerns about future health were not a common reason to stop drinking in our study, which may indicate a lack of health knowledge about alcohol drinking in China as suggested in a previous study in Chinese elderly men and women [42].

Although not designed to be nationally representative, the diverse geographical regions, large sample size in CKB study and rich data on alcohol drinking patterns covered present a good source of data to assess recent alcohol consumption trends for Chinese adults born in 1920s-1970s. Furthermore, to our knowledge, it is the first study to explore longitudinal changes in alcohol drinking among Chinese adults. However, although the expected associations between alcohol intake and blood pressure observed in this study have provided support for the data quality, potential reporting bias of the self-reported alcohol intake data may still exist. Though older participants were slightly less likely to participate in the resurvey, the resurvey response rates were highly consistent across baseline alcohol drinking groups, suggesting that our findings on temporal trends of alcohol drinking were unlikely to be substantially biased by differential resurvey response rates. However, our results may still be partially influenced by the "sick-quitter" effect, i.e. older drinkers had quit alcohol drinking between the study period and the remaining younger heavy drinkers in the weekly drinker group drove up the mean consumption at resurvey. Furthermore, the measure of alcohol use based on "last time drinking" may have limitations subject to time variation [43-45]. Nevertheless, the use of "last time drinking" as a measure of alcohol intake has been supported by findings from our data quality analyses as well as other studies [44, 46-48].

\section{Conclusions}

In summary, among men who drank regularly, the proportion engaging in harmful drinking behaviours has increased in China over the past decade, particularly among younger men, and heavy intake was associated with having other unhealthy lifestyles and health-related risk factors. As alcohol is a modifiable risk factor with reversible health hazards after stopping drinking in the long term, encouraging heavy drinkers to stop drinking before illness develops could have significant benefits to public health in China over the next decades.

\section{Additional file}

Additional file 1: Supplementary tables and figures. (DOCX $118 \mathrm{~kb}$ )

\section{Abbreviations}

CHNS: China Health and Nutrition Survey; CKB: China Kadoorie Biobank; CLHLS: Chinese Longitudinal Healthy Longevity Survey; CNNHS: China National Nutrition and Health Survey; WHO: World Health Organisation

\section{Acknowledgements}

We acknowledge the participants, the project staff, the China National Centre for Disease Control and Prevention, and its regional offices for access to death and disease registries. The Chinese National Health Insurance scheme provides electronic linkage to all hospital admission data.

\section{Funding}

The baseline survey was supported by the Kadoorie Charitable Foundation in Hong Kong. The long-term continuation of the study is supported by the UK Wellcome Trust, the Chinese Natural Science Foundation and the Chinese Ministry of Science and Technology. The UK Medical Research Council, British Heart Foundation and Cancer Research UK provided core funding to the Oxford Clinical Trial Service Unit. The funders had no role in the study design, data collection and analysis, decision to publish or preparation of the manuscript.

\section{Availability of data and materials}

The datasets used and analysed during the current study are available from the corresponding author on reasonable request.

\section{Authors' contributions}

$\mathrm{PI}$ analysed the data and drafted the manuscript. IM, LY and ZC contributed to the conception of this paper, interpretation of the results and the revision of manuscript. $L L$ and $Z C$ designed the study. $L L, Z C, I M, L Y, Y G, Z B, H D, Y C$, $Y T, Z G, S W$ and $Y H$ contributed to data acquisition. All authors critically reviewed the manuscript and approved the final submission. 


\section{Ethics approval and consent to participate}

Ethical approval was obtained from the Ethical Review Committee of the Chinese Centre for Disease Control and Prevention (Beijing, China) and the Oxford Tropical Research Ethics Committee, University of Oxford (UK), and all participants provided written informed consent.

\section{Consent for publication}

Not applicable.

\section{Competing interests}

The authors declare that they have no competing interests.

\section{Publisher's Note}

Springer Nature remains neutral with regard to jurisdictional claims in published maps and institutional affiliations.

\section{Author details}

${ }^{1}$ Clinical Trial Service Unit and Epidemiological Studies Unit (CTSU), Nuffield Department of Population Health, University of Oxford, Oxford, UK. ${ }^{2}$ Medical Research Council Population Health Research Unit (MRC PHRU), Nuffield Department of Population Health, University of Oxford, Oxford, UK. ${ }^{3}$ Chinese Academy of Medical Sciences, Beijing, China. ${ }^{4}$ Meilan CDC, Haikou, Hainan, China. ${ }^{5}$ Suzhou CDC, Suzhou, Jiangsu, China. ${ }^{6}$ Department of Epidemiology and Biostatistics, School of Public Health, Peking University, Beijing, China.

\section{Received: 27 November 2018 Accepted: 31 January 2019}

\section{Published online: 20 February 2019}

\section{References}

1. Gakidou E, Afshin A, Abajobir AA, Abate KH, Abbafati C, Abbas KM, Abd-Allah F Abdulle AM, Abera SF, Aboyans $V$, et al. Global, regional, and national comparative risk assessment of 84 behavioural, environmental and occupational, and metabolic risks or clusters of risks, 1990-2016: a systematic analysis for the global burden of disease study 2016. Lancet. 2017:390(10100):1345-422.

2. World Health Organisation: Global status report on alcohol and health, 2014: WHO; 2014.

3. Cochrane J. Alcohol use in China. Alcohol Alcohol. 2003;38(6):537-42.

4. Hao W, Chen H, Su Z. China: alcohol today. Addiction. 2005;100(6):737-41

5. Hao W, Young D. Drinking patterns and problems in China. J Subst Use. 2009:5(1):71-8.

6. Li H, Borinskaya S, Yoshimura K, Kal'ina N, Marusin A, Stepanov VA, Qin Z, Khaliq S, Lee MY, Yang Y, et al. Refined geographic distribution of the oriental ALDH2*504Lys (nee 487Lys) variant. Ann Hum Genet. 2009;73(Pt 3): $335-45$

7. Tang YL, Xiang XJ, Wang XY, Cubells JF, Babor TF, Hao W. Alcohol and alcohol-related harm in China: policy changes needed. Bull World Health Organ. 2013:91(4):270-6.

8. Jiang $H$, Room R, Hao W. Alcohol and related health issues in China: action needed. Lancet Glob Health. 2015:3(4):e190-1.

9. Hao W, Su Z, Liu B, Zhang K, Yang H, Chen S, Biao M, Cui C. Drinking and drinking patterns and health status in the general population of five areas of China. Alcohol Alcohol. 2004:39(1):43-52.

10. Lee YH, Wang Z, Chiang TC, Liu CT. Beverage Intake, Smoking Behavior, and Alcohol Consumption in Contemporary China-A Cross-Sectional Analysis from the 2011 China health and nutrition survey. Int J Environ Res Public Health. 2017;14(5):493-503.

11. Hao W, Young D, Li L, Xiao S. Psychoactive substance use in three sites in China: gender differences and related factors. Psychiatry Clin Neurosci. 1998; 52(Suppl):S324-8.

12. Li $Y$, Jiang $Y$, Zhang $M$, Yin $P$, Wu F, Zhao W. Drinking behaviour among men and women in China: the 2007 China chronic disease and risk factor surveillance. Addiction. 2011;106(11):1946-56.

13. Ma G-S, D-h X, Hu X-q, Luan D-cK, -Zhi L, Yang X-q. The drinking practice of people in China. Acta Nutrimenta Sinica. 2005;27(5):362-5.

14. Wei H, Derson Y, Xiao S, Li L, Zhang Y. Alcohol consumption and alcoholrelated problems: Chinese experience from six area samples, 1994. Addiction. 1999:94(10):1467-76.

15. Ma G-S, S-m D, L-n H, Y-p L, Hu X-q, Kong L-z. The prevalence of heavy drinking among adults in China. Acta Nutrimenta Sinica. 2009; 31(3):213-7.
16. Li R, Wang D, Chen J, Chai J, Tang M. Regional differences in smoking, drinking, and physical activities of Chinese residents. Asia Pac J Public Health. 2015;27(2):NP230-9.

17. Ma YX, Zhang B, Wang HJ, Du WW, Su C, Zhai FY. Status and trend of alcohol consumption among adults in nine provinces (antonomous region) of China from 1993 to 2006. Zhonghua Yu Fang Yi Xue Za Zhi. 2011;45(4):323-9.

18. Lee YH, Chang YC, Liu CT, Shelley M. Correlates of alcohol consumption and alcohol dependence among older adults in contemporary China: results from the Chinese longitudinal healthy longevity survey. J Ethn Subst Abus. 2018:1-16.

19. World health Organisation: Global status report on alcohol and health 2014 2014.

20. Eigenbrodt ML, Mosley TH Jr, Hutchinson RG, Watson RL, Chambless LE, Szklo M. Alcohol consumption with age: a cross-sectional and longitudinal study of the atherosclerosis risk in communities (ARIC) study, 1987-1995. Am J Epidemiol. 2001;153(11):1102-11.

21. Britton A, Ben-Shlomo Y, Benzeval M, Kuh D, Bell S. Life course trajectories of alcohol consumption in the United Kingdom using longitudinal data from nine cohort studies. BMC Med. 2015;13:47.

22. Knott CS, Bell S, Britton A. The stability of baseline-defined categories of alcohol consumption during the adult life-course: a 28-year prospective cohort study. Addiction. 2018;113(1):34-43.

23. Rehm J, Patra J, Popova S. Alcohol drinking cessation and its effect on esophageal and head and neck cancers: a pooled analysis. Int J Cancer. 2007;121(5):1132-7.

24. Chen Z, Lee L, Chen J, Collins R, Wu F, Guo Y, Linksted P, Peto R. Cohort profile: the Kadoorie study of chronic disease in China (KSCDC). Int J Epidemiol. 2005;34(6):1243-9.

25. Chen Z, Chen J, Collins R, Guo Y, Peto R, Wu F, Li L. China Kadoorie biobank collaborative g: China Kadoorie biobank of 0.5 million people: survey methods, baseline characteristics and long-term follow-up. Int J Epidemiol. 2011;40(6):1652-66

26. Millwood IY, Li L, Smith M, Guo Y, Yang L, Bian Z, Lewington S, Whitlock G, Sherliker $P$, Collins $R$, et al. Alcohol consumption in 0.5 million people from 10 diverse regions of China: prevalence, patterns and socio-demographic and health-related correlates. Int J Epidemiol. 2013;42(3):816-27.

27. World Health Organisation. International guide for monitoring alcohol consumption and related harm. Geneva: WHO; 2000.

28. Emberson JR, Bennett DA. Effect of alcohol on risk of coronary heart disease and stroke: causality, bias, or a bit of both? Vasc Health Risk Manag. 2006; 2(3):239-49.

29. Dumont S, Marques-Vidal P, Favrod-Coune T, Theler JM, Gaspoz JM, Broers B, Guessous I. Alcohol policy changes and 22-year trends in individual alcohol consumption in a Swiss adult population: a 1993-2014 cross-sectional population-based study. BMJ Open. 2017;7(3):e014828.

30. World Health Organisation: Status Report on Alcohol and Health in 35 European Countries 2013; 2013

31. Office for National Statistics: Adult drinking habits in Great Britain: 2017; 2018

32. Yang $L$, Zhou M, Sherliker $P$, Cai $Y$, Peto $R$, Wang L, Millwood I, Smith $M, H u$ Y, Yang G, et al. Alcohol drinking and overall and cause-specific mortality in China: nationally representative prospective study of 220,000 men with 15 years of follow-up. Int J Epidemiol. 2012;41(4): $1101-13$.

33. Poortinga $W$. The prevalence and clustering of four major lifestyle risk factors in an English adult population. Prev Med. 2007:44(2):124-8.

34. Chou KL. The prevalence and clustering of four major lifestyle risk factors in Hong Kong Chinese older adults. J Aging Health. 2008;20(7):788-803.

35. Hart CL, Davey Smith G, Gruer L, Watt GC. The combined effect of smoking tobacco and drinking alcohol on cause-specific mortality: a 30 year cohort study. BMC Public Health. 2010;10(1):789.

36. Kvaavik E, Batty GD, Ursin G, Huxley R, Gale CR. Influence of individual and combined health behaviors on total and cause-specific mortality in men and women: the United Kingdom health and lifestyle survey. Arch Intern Med. 2010;170(8):711-8.

37. Lv J, Yu C, Guo Y, Bian Z, Yang L, Chen Y, Tang X, Zhang W, Qian Y, Huang $Y$, et al. Adherence to healthy lifestyle and cardiovascular diseases in the Chinese population. J Am Coll Cardiol. 2017;69(9):1116-25.

38. Liu S, Zhang M, Yang L, Li Y, Wang L, Huang Z, Wang L, Chen Z, Zhou M. Prevalence and patterns of tobacco smoking among Chinese adult men 
and women: findings of the 2010 national smoking survey. J Epidemiol Community Health. 2017;71(2):154-61.

39. Li S, Meng L, Chiolero A, Ma C, Xi B. Trends in smoking prevalence and attributable mortality in China, 1991-2011. Prev Med. 2016;93:82-7.

40. Chen Z, Peto R, Zhou M, lona A, Smith M, Yang L, Guo Y, Chen Y, Bian Z, Lancaster $\mathrm{G}$, et al. Contrasting male and female trends in tobacco-attributed mortality in China: evidence from successive nationwide prospective cohort studies. Lancet. 2015;386(10002):1447-56.

41. Yang G, Wang Y, Zeng Y, Gao GF, Liang X, Zhou M, Wan X, Yu S, Jiang Y, Naghavi M, et al. Rapid health transition in China, 1990-2010: findings from the global burden of disease study 2010. Lancet. 2013;381(9882):1987-2015.

42. Yin Z, Geng G, Lan X, Zhang L, Wang S, Zang Y, Peng M. Status and determinants of health behavior knowledge among the elderly in China: a community-based cross-sectional study. BMC Public Health. 2013;13(1):710.

43. Rehm J, Greenfield TK, Walsh G, Xie X, Robson L, Single E. Assessment methods for alcohol consumption, prevalence of high risk drinking and harm: a sensitivity analysis. Int J Epidemiol. 1999;28(2):219-24.

44. Kesmodel U. Self reported alcohol intake in pregnancy: comparison between four methods. J Epidemiol Community Health. 2001;55(10):738-45.

45. Dawson DA. Methodological issues in measuring alcohol use. Alcohol Res Health. 2003;27(1):18-29.

46. Ekholm O, Strandberg-Larsen K, Christensen K, Gronbaek M. Comparison of assessment methods for self-reported alcohol consumption in health interview surveys. Eur J Clin Nutr. 2008;62(2):286-91.

47. Stockwell T, Donath S, Cooper-Stanbury M, Chikritzhs T, Catalano P, Mateo C. Under-reporting of alcohol consumption in household surveys: a comparison of quantity-frequency, graduated-frequency and recent recall. Addiction. 2004; 99(8):1024-33.

48. Knibbe RA, Bloomfield K. Alcohol consumption estimates in surveys in Europe: comparability and sensitivity for gender differences. Subst Abus. 2001;22(1):23-38.

Ready to submit your research? Choose BMC and benefit from:

- fast, convenient online submission

- thorough peer review by experienced researchers in your field

- rapid publication on acceptance

- support for research data, including large and complex data types

- gold Open Access which fosters wider collaboration and increased citations

- maximum visibility for your research: over $100 \mathrm{M}$ website views per year

At $\mathrm{BMC}$, research is always in progress.

Learn more biomedcentral.com/submissions 